\title{
STRUCTURAL ADJUSTMENT: A TREASURY EXPERIENCE
}

Jonas P. Kipokola*

\section{INTRODUCTION}

Most sub-Saharan African countries (SSACs) have, for up to a decade, been implementing Structural Adjustment Programmes (SAPs) of one form or another, to revive their economies and put them on a sustainable footing. For most of these countries the SAPs are now collaborative arrangements with the Bretton Woods Institutions (World Bank - IBRD and the International Monetary Fund - IMF), other international financial institutions and bilateral donors. The SAPs are strictly speaking a phenomenon of the 1980 s and 1990s. It is also noteworthy that invariably the SAPs have been coordinated at the Treasury, partly because these programmes have also been strategies for mobilizing the requisite external resources for implementing the SAPs and partly because of their emphasis on macro fiscal, monetary and exchange rate issues.

After a decade or more of learning by doing, Treasuries, Planning Ministries and Central Banks of SAP countries in sub-Saharan Africa (SSA) have accumulated valuable experience in Programme design and implementation. It is important that this experience should be pooled and shared to improve the effectiveness of SAPs in SSACs more generally. The IDS (Dar es Salaam/Sussex) seminars, by deploying SAP practitioners as resource persons and participants are an instrument to this end as well as a functioning example of a North-South partnership.

With regard to Tanzania, economic management through SAPs is a phenomenon beginning in the mid-1980s. The Economic Recovery Programme (ERP-I) which was launched in July 1986 as a three-year economic management framework (1986/87-1989/90) after prior negotiations beginning in late 1984 turned out tobe an effective strategy, in that an appropriate package of policies and actions was able to trigger external resources to support its implementation and that it enabled the feeble recovery of 1984-85 to gather momentum for the next six years.
During the early 1980 s, efforts by the Government of Tanzania to arrest the deterioration of the economy had been unsuccessful. The 1980 Standby Arrangement with the IMF was suspended after only one quarterly drawing, for failure to satisfy the performance tests. The 1981 National Economic Survival Programme (NESP) was a crisis approach to foreign exchange scarcity, and although export receipts increased during that year, the recovery was not sustained in 1982. The Structural Adjustment Programme (SAP), also planned for three years $(1982 / 83-1984 / 85)$ and the product of high-owned external professional cum technical inputs, failed to attract complementary external resources as well as being less than enthusiastically received by domestic professionals and decision takers. By 1983-84 the view that sustained adjustment without substantial external support was impossible and therefore that a programme for negotiation with the Fund and Bank needed to be agreed domestically had achieved the broad professional personnel and decision taker support it had not enjoyed when first put forward by the Treasury in 1981 .

ERP-I was initiated and drawn up by the Government of Tanzania in late 1983-early 1984 as a medium term plan and strategy for reviving the economy. The initial draft was discussed extensively through workshops and seminars, involving participation from the Government sector, the parastatal and private sectors, and academic institutions. This discussion was directed to three objectives: (i) brainstorming - to improve the draft, (ii) informing and to educating as to realities and options; (iii) enlisting broad based internal support for the programme. Following the internal discussions, the IMF was approached in late 1984 to evaluate the programme and render support. Fortunately, the Fund was responsive. Equally important the Bank agreed to develop initial programming and to hold a pledging conference exercise prior to (though contingent on) conclusion and implementation of a Fund agreement in order to reduce the lag between initial shocks and resource inflows. Acceptance by the IMF of the need

\footnotetext{
- Deputy Principal Secretary/Deputy Secretary: National Planning Commission, United Republic of Tanzania and sometime Deputy Secretary Treasury.
} 
to associate growth with adjustment following conclusions of the Annual Meetings of the World Bank and IMF in Seoul, South Korea in September, 1985 probably played a crucial role in sustaining GOT - IMF SAP collaboration under ERP-I, ERP-II (ESAP) and post-ESAP. Tanzania always held very strong views on the need for low income countries to be assisted to adjust with growth, not with a substantial initial contraction only subsequently reversed by renewal of growth.

\section{THE CIRCUMSTANCES FOR SAPS IN SSACS}

SAPs in SSACs may be generalized to represent belated macroeconomic management responses to situations of excessive policy and structural distortions built up over a number of years and especially from 1979 onward. The causal factors for the economic deterioration vary from country to country, but in all cases both internal and external factors have been at play. In the case of Tanzania, the Arusha Declaration (1967) which shifted emphasis to public ownership of property, increased role of government and government intervention in economic activity is an important background for the SAPs in the 1980s. External factors, like the oil shocks (1973-4 and 1979-80), droughts (1973/74, $1979 / 84)$ the break-up of the East African Community (1977), the 1978 coffee price collapse and the war following the Uganda invasion (1978-79) were important. In particular lack of any adequate and timely macro-economic policy responses over 1978-1979 and major domestic disagreements on policy over 1981-1984 were crucially important.

Consequently, the situation for Tanzania prior to SAPs, which is typical for SSACs, was one of economic and financial crisis. Real GDP growth was negative for three consecutive years (1981-1983) and rose at less than population growth in 1984 and 1985. The output of agricultural crops fell or stagnated, or was perceived to do so, while crop export volumes decreased sharply. Industrial capacity utilization declined from 60-70 per cent in the late 1970 s to a dismal $20-25$ percent by 1985 while absolute industrial output declined sharply, falling to less than 5 per cent of GDP in 1985, down from 12 per cent in 1978. Domestic inflation accelerated to over 30 per cent in 1984 compared to 12 per cent in 1977-79; the overall budget deficit increased rapidly to over 16 per cent of GDP in
$1981 / 82$ though it was squeezed back to about 10 per cent in $1984 / 85$. Side by side with - and via inflation contributing to - a marked decline in real wages, recourse to domestic bank credit was financing about 75 per cent of the budget deficit 1983/84. Official reserves had been exhausted, external payments arrears had accumulated to US\$ $900 \mathrm{~m}$. in 1986 compared to US\$ $500 \mathrm{~m}$. in 1983 and negligible in 1978. Medium and long term debt had escalated from US\$2.8bn. in 1983 to US $\$ 3.8 \mathrm{bn}$. in 1985, despite which imports had been severely curtailed, declining by 40 per cent in real terms between 1980 and 1983 . Economic infrastructure, including lorry fleet and railway rolling stock, had deteriorated badly due to lack of maintenance and replacement. The quantity and quality of social services, in which the Government had invested heavily in the post-independence period, had also deteriorated due to budgetary underfunding. An acute shortage of consumer goods and production inputs in the first half of the 1980s, peaking in 1983, was a visible manifestation of the economic crisis prevailing in Tanzania in the period immediately before the SAPs.

\section{POLICY RESPONSE AND ECONOMIC STRATEGY}

ERP-I was launched in July 1986 as a three year economic management strategy in collaboration with the IMF, World Bank, other international financial institutions and bilateral donors. The ERP entailed macro and sectoral measures, with detailed action plans and monitorable performance criteria. Key policy areas included the exchange rate, trade liberalization, interest rates, producer prices, the budget, credit creation and money supply growth.

In ERP-I (1986/7-1988/9) efforts were directed mainly to the productive sectors and economic infrastructure, while in ERP-II or ESAP (1989/90$1991 / 2)$ emphasis was shifted to the social sectors, especially education and health, and financial sector reform; followed by public sector reform (Parastatal and Civil Service). After ERP-II, a Rolling Plan and Forward Budget (RPFB) have been introduced, starting in 1993/94, to take the place of the PFP (Policy Framework Paper) and the Annual Plan. Like the PFP, the RPFB has a three year framework which is rolled forward every year, and because it combines the PFP and the Annual Plan, 
it has been possible to have in one document (i) macroeconomic policies (ii) sectoral policies, and (iii) the investment programme.

\section{PERFORMANCE RESULTS}

The key economic indicators have stayed encouraging throughout the SAP period (ERP-IM ERP-II and after). Real GDP growth has averaged about 4 per cent compared to 1 per cent for 1980-85; the rate for agriculture is 4.5 per cent against 0.6 per cent for 1980-85 (admittedly during a run of good weather years); while industry's is 5.1 per cent compared to minus 4.5 per cent per annum for the period 1980-85. Performance improvements have been constrained by institutional and structural bottlenecks, such as marketing arrangements, transportation and processing capacity. These are very important long term issues for sustainable growth and the Government has been addressing them. Inflationary pressures have been abated (from more than 30 per cent in 1986 to about 20 per cent) and future prospects look good due to financial sector reforms and more targeting of policies and strategies. The fiscal imbalance has also been substantially corrected, albeit more by a substitution of external grants for domestic bank borrowing than by raising domestic revenues relative to expenditure. Extensive structural and institutional reforms have been achieved in agriculture, the financial sector, domestic and foreign trade regimes, and foreign exchange management. Substantial improvements - rehabilitations - have been achieved in transportation and social infrastructure. Individual initiatives and the role of market forces have been vigorously revived; while the excessive size of the public directly productive sector has been programmed for substantial reduction as part of economic restructuring. The problem of consumer goods and production inputs availability has been substantially abated under Tanzania's SAPs. This result relates partly to trade liberalization but more basically to donor provision of funding for open general license (OGL) imports.

The balance of payments position has, however, remained precarious, and external sector performance has on the whole been unsatisfactory despite concerted efforts. Similarly, the external debt problem has not been tackled durably inspite of (or perhaps because of) repeated Paris Club reschedulings and occasional debt write-offs by bilateral creditors.

\section{SOME LESSONS AND CONCLUSIONS FROM TREASURY EXPERIENCE (WITH REFERENCE TO TANZANIA)}

In respect to appropriateness of approach: it seems the ERP-I and ESAP have been suitable strategies for structural adjustment in Tanzania. Under the ERP-I, ESAP, PFPs, SAFs, ESAF and policybased lending by the World Bank Group, it has been possible to address policy reform and structural adjustment issues simultaneously while safeguarding the growth objective.

Uses of broad based consensus and a home-grown programme are rather evident in the Tanzania case. The fact that Tanzania has been a country committed to a transition to socialism (albeit not to a MarxistLeninist state) and that both economic adjustment, and reversion to multi party (as contrasted to single party) competitive elections, started before the changes in Eastern Europe, meant that the Government had to proceed cautiously by building toward a broad-based consensus. In this regard the ERP approach which involved adequate prior preparation and broad participation was very helpful. The same caution had to apply in negotiations with the IMF first to roll over/redraw and - with ESAF - to increase drawings as well as to secure a 'seal of approval', and for policy-based lending by the World Bank Group. In this respect, the creation of an interministerial technical group of officials for the purpose, coordinated by the Treasury, proved effective, in so far as intra-governmental unity is concerned. It also helped ensure that the tensions resulting from broad agreement on strategy but substantial divergences of perspective on specific policies as well as on sequencing and timing did not lead to deadluck and/or to programme collapse.

The importance of timely action (costs of initial delays) is clear from the Tanzanian case. Delays in undertaking appropriate adjustment policies exacerbate the underlying economic weakness, thereby entailing larger doses of action in future adjustment policies. In turn, this makes decisions to adjust more difficult and the adjustment measures when they get taken more painful. For Tanzania, opportunities for corrective action were missed or postponed until a crisis situation developed. But by 
the same logic from mid-1984 when Tanzania adopted most of the measures for a SAP, the lag in external response weakened initial results and by mid 1985 endangered continuity of policy.

Prioritization in a situation of limited resources requires concentration of effort on those of greatest and most rapidly visible recovery impact. For Tanzania the productive sectors of agriculture and industry, together with transportation were assigned phase one priority, relatively effectively for agriculture but with serious unexpected lags in the case of industry.

Real cum financial sectors adjustment are not opposites. Where both sectors have been distorted and are inefficient, as has been the case for Tanzania, it seems adjustment in both sectors should be undertaken simultaneously. In Tanzania we sequenced real sectors before financial sector reforms, and this has proved costly especially in terms of inability to control credit creation, money supply growth and inflation. Arguably, however, the underlying monetary problem is both real and political, not purely monetary or technical. No Tanzanian government has been willing to allow a situation in which no buyer had credit to purchase peasant crops and the efficiency/bad debt record of both the public (Marketing Authority) and main private (Co-op) sectors since 1976 has - despite massive foreign advice and policy design inputs - been disastrous.

Pace of adjustment is, in practice, a barrier to sustain-ability. Structural adjustment is slow, and requires patience and sustenance of efforts. This is particularly so because for countries like Tanzania, in addition to adjusting economic and institutional systems, there may also be a need to create new ones. However, difficult changes each year are sustainable only if gains from past changes are evident, not least is the run up to elections in 1994 (local government) and 1995 (national).

Choice of policy instruments is an area of considerable ambivalence. We think that IMF programmes overload the exchange rate as a policy instrument. Whereas it is true the exchange rate is an important policy instrument for restoring external sector balance, it is also true that it cannot work if important cooperative factors do not exist. In the case of Tanzania, the assessment is that these other factors issues have not been adequately recognized and considered by the Bretton Woods institutions. The same is true of the interest rate structure. Highly negative real interest rates do lead to credit allocation problems but very high positive real interest rates crowd out long term productive investment.

The feasibility of performance benchmarks, as now designed, in an economy subject to massive weather and terms of trade shocks is open to doubt. While performance tests are desirable and indeed necessary for monitoring programme implementation progress, the experience has been that some targets have been set which were clearly unachievable right from the start and others were attainable only on favourable weather, terms of trade and aid flow timing assumptions. In the case of Tanzania, this has been particularly true for credit ceilings, and money supply growth targets. One factor here has been an inadequate understanding of the dynamics of institutional reforms in low income economies e.g. prompter Treasury payment of bills raises the cash flow fiscal deficit in that year and is recorded as a worsening of fiscal performance. Other targets failed to take into consideration weather (not simply bad weather - good weather increases the amount of credit needed to buy crops) and terms of trade vagary.

The role of the state and private sector has become an area of pendulum swings which may or may not be corrections toward an equilibrium. Because many sub-Saharan African countries have overextended public enterprise sectors, privatization and divestment are bound to be a necessary part of structural adjustment programmes. Nevertheless, there are many pertinent issues regarding the extend to which privatization and divestment should be taken, and the roles and State should continue playing in the business enterprise sector. If the private sector is as underdeveloped as it is in Tanzania, it seems there is a need to recognize a fairly extended role of the State in enterprise development, especially in the short to medium term. Premature sales of shares or enterprises leading to near monopolization of purchases to foreign enterprises plus minority citizen communities will lead to a backlash threatening both investment stability and - even more important - the liberal, non-racial character of Tanzania.

Market forces and trade liberalization is an issue which requires serious discussion, because as part of adjustment programmes the Bretton Woods 
institutions have been pushing external trade liberalization measures without adequate consideration of the existence in the adjusting countries of conditions for fair competition or of the need to project local (infant) industries. Indeed they have chosen to ignore that domestic market protection parallel to industrialization has characterized almost all successful manufactured export break-throughs (as well, it is true, as the industrial sectors which failed to achieve efficiency).

\section{CONCLUSIONS}

A lot has been learnt in the process of SAPs in SSA:

1 consensus building has to be part and parcel of designing structural adjustment programmes;

2 For adjustment to work, timely decisions and decisive actions are crucial;

3 Serious local technical capacity is necessary if a country is to work with and benefit adequately

\section{REFERENCES}

Government of Tanzania Documents, (Article IV Consultation Reports, SAP, ERP, ESAP, Economic Surveys)

- Staff Working Papers from the specialized capacity of the Bretton Woods institutions;

4 While the quantum of external resources is important per se, their nature and timing can make an equally big difference to the success or failure of a programme.

These aspects, especially that of timing should receive more attention in the future. Capacity building in economic management is crucial for the long term economic sustainability of sub-Saharan Africa countries. Finally, structural adjustment is a slow process which requires patience and sustainance of efforts: the task for sub-Saharan Africa may be not only to adjust economic and institutional systems, but to create them as well. This means that programmes to correct macro-imbalances in these countries should be designed in the context of medium to long term time-frames. Three year rolling stages may be suitable - three year total programmes are hopelessly and self defeatingly optimistic.

World Bank, 1991, Tanzania Economic Report: Towards Sustainable Development in the 1990s

, World Development Report 1991: The Challenge of Development

World Bank and IMF Staff Papers, various 